\section{MORAY, ENIGMA DE LA INGENIERÍA INCAICA}

\author{
KENNETH WRIGHT, RUTH WRIGHT, ALFREDO \\ VALENCIA \& GORDON MCEWAN \\ UNIVERSIDAD NACIONAL DE INGENIERÍA. \\ LIMA-PERÚ, 2017.
}

RESEÑA DE EDGAR RODRÍGUEZ ZUBIATE

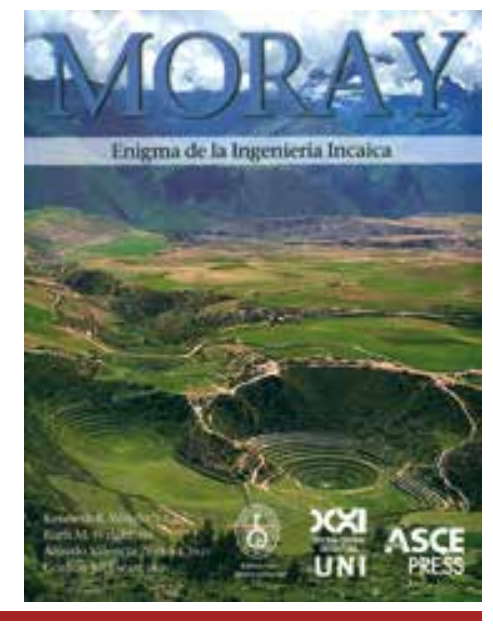

Este libro presenta una valiosa investigación respecto a la ingeniería civil incaica, en lo que resulta un aporte extraordinario a la formación de profesionales que tomen como base la herencia dejada por los antiguos peruanos, y que contribuirá a que se sientan orgullosos del legado de sus obras de ingeniería.

Moray, construida durante el siglo XV y comienzos del siglo $\mathrm{XVI}$, consiste en un conjunto de cuatro hoyos de diferente tamaño, compuestos de terrazas circulares construidas aprovechando depresiones naturales del terreno, que cubre una extensión de 37 hectáreas. El hoyo más pequeño tiene aproximadamente 39.6 metros de diámetro y el más grande 122 . En cada hoyo hay una fila simple de caídas de agua, adecuadamente colocadas en serie. El conjunto se encuentra ubicado a 7 kilómetros de Maras, a una altitud por encima de los $3450 \mathrm{~m} \mathrm{s.} \mathrm{n.} \mathrm{m.}$

Resulta conveniente adelantar una conclusión del estudio, en tanto contradice lo comúnmente aceptado, al indicar que no hay evidencia que apoye que Moray fue una estación de investigación agrícola, sino, más bien, un lugar donde se realizaban ceremonias religiosas.

Es importante resaltar cómo ha sido estructurado el libro, pues es redactado tomado en cuenta los estándares de un proyecto de ingeniería civil, lo cual no solo le da un gran valor al trabajo de investigación, sino que define el orden de sus partes. La obra se compone de trece capítulos.

En el primero se describe Moray a partir de diferentes aspectos, entre los que resaltan las características geológicas de la zona, que explica por qué se formaron los hoyos de manera natural, que fueron la base para la construcción del complejo de Moray. Se destaca que la zona está geológicamente caracterizada por la formación de Maras, la cual es altamente calcio, y, por ello, está sujeta a la formación de cavidades y sumideros.

El segundo capítulo trata de la planificación en la ingeniería civil y busca responder a la interrogante sobre cómo y por qué se concibieron, diseñaron y construyeron las terrazas en los hoyos de Moray. Estos fueron estéticamente ordenados, mediante la planificación de terrazas en enormes círculos concéntricos y óvalos, lo cual requirió de la colocación de relleno. Asimismo, en el fondo de los hoyos se colocó un filtro inverso para la percolación del agua con grandes rocas, lo cual definió una zona plana. Es importante resaltar la distribución de los flujos de agua, proveniente de un manantial principal y de otro secundario, que son conducidos mediante canales a cada hoyo, en los cuales se planificó que el agua cayera en cada una de las terrazas, mediante una serie de caídas de agua excavadas en roca, hacia la parte inferior, donde se infiltran. Los autores manifiestan que los ingenieros incas decidieron no regar las terrazas circulares, pues el agua de regadío contribuiría a la inestabilidad del lugar.

El tercer capítulo trata sobre la tecnología incaica, y en él se manifiesta que la perfección geométrica de las obras denota una planeada uniformidad que solo calcárea, rica en carbonato y sulfato de pudo ser lograda mediante estrictos estándares de diseño.

Sucesivamente, en el capítulo cuarto se estudia la hidrología e hidrogeología de la zona; el capítulo cinco trata de aspectos de ingeniería hidráulica, presenta un estudio hidráulico de los canales de distribución e identifica la presencia de pequeños reservorios que sirven para regular los caudales procedentes de los manantiales; el capítulo seis se centra en la ingeniería de construcción, incluye cada uno de las componentes del complejo; el capítulo siete trata sobre agricultura, donde los autores manifiestan que este estudio representa un paso importante en sus procesos de investigación, y es parte de un cuidadoso y completo análisis.

Un capítulo que cabe destacar es el octavo, pues, tomando con base de lo estudiado en los capítulos anteriores, es allí donde se demuestra que Moray no fue una estación de investigación agrícola. A continuación, el capítulo nueve trata sobre rocas labradas encontradas en Moray, lo que refuerza el concepto de que fue más bien un lugar destinado a ceremonias religiosas.

Los demás capítulos tratan sobre las comunidades incaicas cercanas, el Imperio inca y su entorno. Asimismo, Ruth Wright describe de forma detallada cómo hacer un recorrido adecuado a pie al visitar Moray. Las conclusiones del estudio se presentan en forma resumida en el capítulo 11.

Este libro representa un estudio de ingeniería muy importante, pues servirá como base para futuras investigaciones respecto de temas que hace falta estudiar con más profundidad. 